\title{
A national register-based study of paediatric varicella hospitalizations in Denmark 2010-2016
}

\author{
I. G. HELMUTH ${ }^{1,2 *}$, A. POULSEN ${ }^{1}$ AND K. MØLBAK ${ }^{2}$ \\ ${ }^{1}$ Department of Paediatrics and Adolescent Medicine, Rigshospitalet, Copenhagen, Denmark \\ ${ }^{2}$ Department of Infectious Disease Epidemiology, Statens Serum Institut, Copenhagen, Denmark
}

Received 20 January 2017; Final revision 1 June 2017; Accepted 17 July 2017;

first published online 14 August 2017

\section{SUMMARY}

Varicella, usually a mild disease of childhood, can also cause complications and hospitalization. Universal varicella immunization is implemented in several countries worldwide, but not in Denmark. Taking advantage of unique national registers, we aimed to estimate the incidence of paediatric varicella hospitalizations and assess determinants for hospitalization. For this purpose, we designed a nationwide, retrospective register study of paediatric varicella hospitalizations and applied a case-cohort design and logistic regression analysis comparing hospitalized varicella patients to a sample of the entire paediatric population in Denmark. Varicella patients were identified in The Danish National Patient Register and referents were randomly selected from the Danish Civil Registration System. The incidence of paediatric varicella admissions was $11 / 100000$ children $0-18$ years of age/year. Of admitted children $67 \cdot 1 \%$ had complications and $30.0 \%$ had underlying disease. All categories of underlying disease significantly increased the odds of hospitalization as well as male gender and not having been born in Denmark. In conclusion, we found a considerable burden of paediatric varicella disease in Danish hospitals, of similar magnitude as in other European countries comparable to Denmark. With this study we have provided epidemiological data needed for considering implementation of varicella vaccine in Denmark.

Key words: Paediatric varicella hospitalizations, varicella complications, varicella epidemiology, varicella zoster virus.

\section{INTRODUCTION}

Varicella, caused by varicella zoster virus (VZV), is an acute febrile illness characterized by a universal vesicular rash. Varicella is usually mild, but can also result in complications and hospitalization. In European countries without universal vaccination, varicella affects about $90 \%$ of children before the

\footnotetext{
* Author for correspondence: I. G. Helmuth, Department of Infectious Disease Epidemiology, Statens Serum Institut, Artillerivej 5, 2300 Copenhagen S, Denmark.

(Email: IDGK@ssi.dk)
}

age of 10 years [1-3]. After primary infection, the virus lies dormant in nerve ganglia and can later reactivate to cause herpes zoster - a painful rash usually confined within a dermatome [1].

Varicella is preventable by a live-attenuated vaccine available as a monovalent vaccine or in combination with measles-mumps and rubella. Varicella vaccination has shown to be both safe and effective in preventing varicella, but less so in preventing herpes zoster [1, 2, 4]. WHO recommends that childhood varicella immunization is considered in countries where the disease has a high impact on public health and where high vaccination coverage $(85-90 \%)$ can 
be achieved [5]. Countries that have implemented universal varicella immunization including the USA, Germany and Australia have experienced a marked decrease in disease burden [6-11]. Rates of hospitalization, complications and severity of varicella has been described for several European countries [12-15], but only few have adopted the vaccine in national immunization schemes $[15,16]$. Results of epidemiological studies on varicella vary across Europe due differences in study design, urbanization and patterns of childcare $[15,16]$. Hence, when deciding on national strategies for childhood varicella vaccination, national studies on disease epidemiology are essential. In Denmark, varicella vaccination is not a part of the national childhood immunization scheme, varicella is not notifiable and the burden of disease has not been assessed on a national level.

The primary aim of this study was to estimate the incidence of paediatric varicella hospitalizations in Denmark and describe characteristics of children hospitalized with varicella. The secondary aim was to assess determinants for paediatric varicella hospitalization. To meet this objective, we took advantage of unique national registries allowing for unbiased estimates and an analytic epidemiological approach.

\section{METHODS}

The study was designed as a retrospective, nationwide population-based register study. We applied a casecohort design and logistic regression analysis to assess determinants for hospitalization with varicella comparing hospitalized paediatric varicella patients to a randomly selected reference group representing the entire paediatric population in Denmark.

Denmark has a population of 5.6 million. Healthcare is tax funded and free of charge for all residents. The five regions in Denmark are responsible for providing healthcare. At birth, all residents are assigned a unique Civil Registry number (the CRS-number) used to register the utilization of healthcare services. The CRS-number allows for linkage between Danish registries at individual level [17, 18]. Patients that are not Danish citizens at time of hospitalization are assigned a temporary unique CRS-number.

The Danish National Patient Register (DNPR) contains information on all in- and outpatient contacts for all hospitals in Denmark. It includes the start and end date of in- and outpatient contacts and discharge diagnoses. Diagnoses are coded according to the ICD10 (International Classification of
Diseases 10th revision). For diagnoses, it is possible to register one primary diagnosis, while there is no upper limit to the number of secondary diagnoses $[18,19]$. The DNPR does not contain information from general practitioners. However, in 2014 one of the five Danish regions, the Capital Region, introduced a new hospital-based system for primary care patients seen out-of-hours, and therefore these are registered in DNPR as outpatient contacts from January 2014.

We included all hospital contacts of children $<18$ years of age in DNPR with a primary or secondary diagnosis of varicella (ICD10 codes B01-B019 and P358A) in any diagnostic position in a period of 6 years from 1 January 2010 to 31 December 2015. We included patients with a temporary CRS-number and patients from Greenland admitted in Danish hospitals as they contributed to the overall burden and could represent refugees or migrants.

We excluded patients with a start date before 2010, outpatient contacts lasting $>2$ months because a disease onset could not be determined and patients registered in 2014-2015 at departments serving paediatric primary care patients seen out-of-hours in the Capital Region.

We grouped patients in two groups: (1) admitted patients were defined as patients coded as inpatients with admissions lasting $\geqslant 1$ day and (2) outpatients defined as patients coded as inpatients for $<1$ day or outpatients. Collectively we will refer to these two groups as 'hospitalizations'.

For inpatients with several discharge diagnoses of varicella within a short time period, we created courses of admissions. This was done because transfer between hospitals or between departments in one hospital in many cases was coded as individual admissions in DNPR, and admission time could therefore be incorrectly estimated unless we reconstructed the full course of admission. Several admissions for the same patients were defined as one course of admission if the timespan between discharge and a new admission was $<1$ day. Length of admission was counted as total days between the first admission and the last discharge.

We defined the date of varicella as the first day of admission or date of first outpatient visit. Only first course of admission or outpatient visit was analysed.

To assess complications to varicella, we extracted all other primary or secondary discharge diagnoses in any diagnostic position given with a varicella code in any diagnostic position. ICD10 codes used 
to define complications to varicella are available in Supplementary material and were completed in cooperation with a specialist in paediatric infectious diseases.

To assess underlying medical conditions, we extracted all primary or secondary discharge diagnoses in any diagnostic position in DNPR for included patients up to 5 years before to 3 weeks after the varicella date. ICD10 codes defined as an underlying condition are available in Supplementary material and were completed in cooperation with a specialist in paediatric infectious disease. For conditions that could be both a complication and an underlying disease, a time restriction for the underlying disease was added.

The Danish Civil Registration System (CRS) contains individual-level information on the entire population of Denmark including vital and migration status [17]. We obtained country of birth, province of residence at date of varicella and vital status for cases up to 90 days after varicella date.

\section{Statistical analysis}

We performed a descriptive analysis of the paediatric varicella hospitalizations. We described continuous variables in medians, IQR and maximum values since all continuous variables were skewed to the right. We calculated incidence using the census of 2013 as the denominator $(1 \cdot 190 \cdot 301$ children $0-18$ years of age). Categorical data were compared using a $\chi^{2}$ test.

We used a case-cohort design and performed a logistic regression analysis to assess determinants for a hospitalization with varicella comparing all the identified varicella patients to a sample of the entire paediatric population of Denmark (i.e. referents). In this approach, cases were allowed to be sampled for the reference group. We randomly selected 10 referents for each case from CRS matched for year of birth to ensure equal distribution of age groups between cases and referents. We excluded referents if they were born after the date of varicella for the corresponding case or if they were born abroad and had not entered Denmark at date of varicella for the corresponding case. This was done to ensure that cases and referents would have equal time at risk when assessing underlying diseases. If a case had no referents after running the exclusion procedures, we randomly re-sampled new referents so that each case had at least two referents. Underlying diseases were assessed for referents as for cases up to 5 years before and 3 weeks after the date of varicella for the corresponding case.

For the logistic regression model, we evaluated the following independent variables by univariable analysis while controlling for the matching factors (year of birth categorized in nine categories and date of varicella for the case categorized in years): gender, underlying disease (categorized according to Supplementary material) and country of birth (dichotomized into Danish or non-Danish origin due to high number of unknown country of birth among the cases). Country of birth was categorized as non-Danish if it was unknown. Variables associated with being a case at a significance level of $10 \%$ were considered for the multivariable model and subsequently eliminated if they did not contribute at a significance level of 5\%. The final model was controlled for region of residence and the matching factors.

To evaluate relevant interactions in the logistic regression model, we also performed the analysis stratified on the following age groups: $0-1$ years of age, 2-3 years of age and $>4$ years of age (data not shown). In the stratified analysis, all categories of underlying disease were independently associated with the outcome (except for a history of prematurity in the age group $>4$ years of age). The effect size differed from the overall model for some categories of underlying disease, but overall findings remained consistent but with wider confidence limits. At the chosen level of categorization of diagnosis, a formal test for interaction was impossible to conduct due to sparse data.

To assess determinants for admission $\geqslant 1$ day, we also conducted a logistic regression analysis only among cases. We assessed the following independent variables by univariable analysis sex, age (dichotomized in age $>$ or $<1$ year), country of birth, underlying disease and complications to varicella. The final model was controlled for region and year of hospitalization.

Analyses were performed using STATA (version 12.1, STATA, College Station, Texas, USA).

\section{Ethical considerations}

The study was notified to the Danish data protection agency under the record number 2008-54-0474. Danish legislation does not require ethical board approval or informed consent from study participants in register studies [20]. 


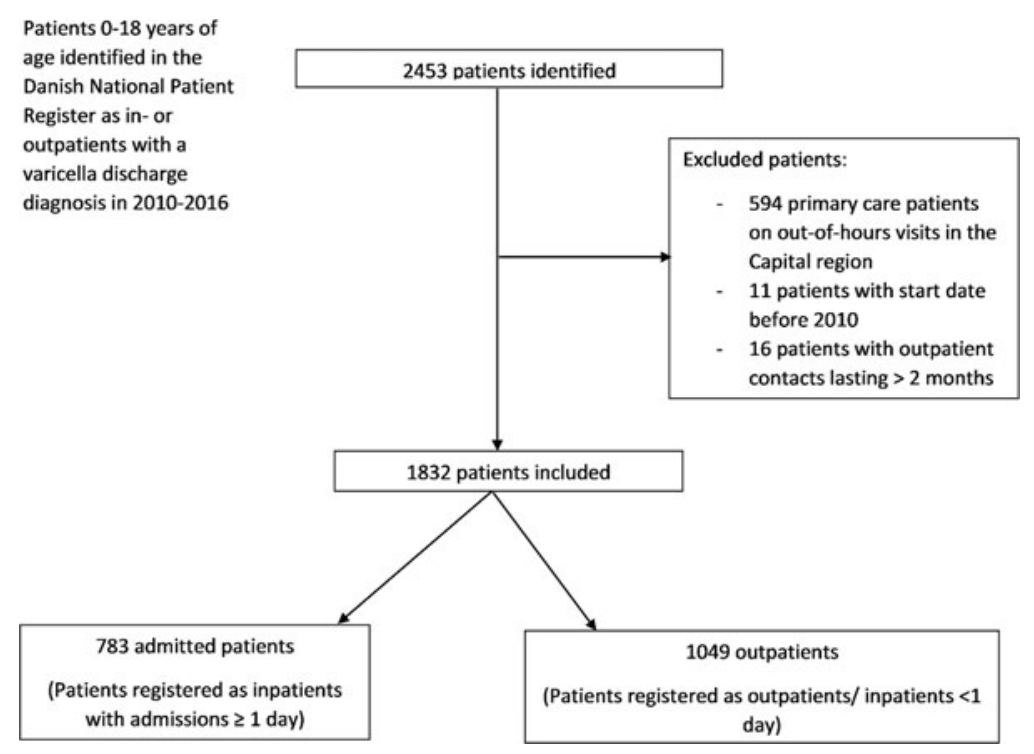

Fig. 1. Flowchart of in- and exclusion of patients hospitalized with varicella in Denmark 2010-2016.

\section{RESULTS}

\section{Descriptive epidemiology}

In DNPR, we identified 2857 hospitalizations, 1592 inpatient contacts and 1265 outpatient contacts. The total number of unique patients was 2453 . Of those 621 were excluded; 594 patients were primary care patients on out-of-hours visits in the Capital Region, 11 patients were registered with a start date before 2010, 16 patients had outpatient contacts lasting $>2$ months. A total of 1832 patients were included; 783 patients registered as inpatients with admission $\geqslant 1$ day and 1049 as outpatients/inpatients $<1$ day (collectively referred to as outpatients) (Fig. 1). A total of 41 patients $(2 \cdot 2 \%)$ were registered with a temporary CRS-number, and four patients were registered as citizens of Greenland.

The hospitalizations displayed a seasonal variation with the highest number of contacts in late winter and early spring and a nadir in August and September (Fig. 2).

General characteristics of patients hospitalized with varicella are presented in Table 1 and the frequency of registered complications for all patients and admitted patients in Table 2. Most patients were previously healthy children between 1 and 4 years of age. The median age was 2 years (IQR 1-3). Underlying disease was identified in $22.1 \%$ of short contact patients and $30.0 \%$ of admitted patients $(P<0.001)$. The frequency of complications was $31 \cdot 1 \%$ for outpatients and $67 \cdot 1 \%$ for admitted patients $(P<0 \cdot 001)$. Of children with underlying disease, $47 \cdot 3 \%$ were registered with

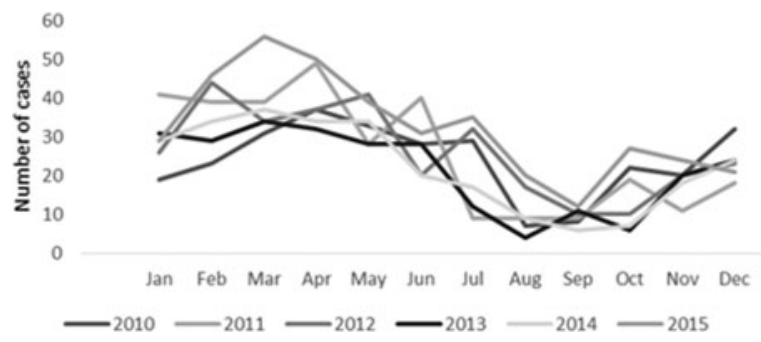

Fig. 2. Seasonal variation of paediatric varicella hospitalizations in Denmark 2010-2016.

complications vs. $46 \cdot 2 \%$ of patients without underlying disease $(P=0.66)$. The most common complications were from the central nervous system including febrile seizures, followed by complications of the skin and lower airways $(17 \cdot 5 \%$ and $11 \cdot 0 \%$ of admitted patients, respectively). The median age of children with complications of the central nervous system excluding febrile seizures was 4 years (IQR 2-8, max $15)$, while the median age of children with complications of skin and soft tissue was 2 years (IQR 1-3, $\max 13)$.

Two patients were registered with congenital varicella (ICD10 code P358A).

Of the 1832 patients, $94 \cdot 1 \%$ were born in Denmark. For the remaining 109 patients, the country of birth could be determined for 67 patients; patients with a non-western region of birth (Greenland, The Middle east and North Africa including Pakistan, Afghanistan and Turkey, Southeast Asia, Latin America and Africa) were older (median age 4 
Table 1. General characteristics of paediatric patients hospitalized with varicella in Denmark 2010-2016 identified in the Danish National Patient Register

\begin{tabular}{|c|c|c|c|}
\hline & All patients & Outpatients $^{\mathrm{a}}$ & Admissions $^{\mathrm{b}}$ \\
\hline No. of patients, $N(\%)$ & 1832 & $1049(57 \cdot 3)$ & $783(43 \cdot 7)$ \\
\hline Females $N(\%)$ & $832(45 \cdot 4)$ & $483(46 \cdot 0)$ & $349(45 \cdot 6)$ \\
\hline \multicolumn{4}{|l|}{ Age groups $N(\%)$} \\
\hline 0 years & $399(21 \cdot 8)$ & $205(19 \cdot 5)$ & $194(24 \cdot 8)$ \\
\hline $1-4$ years & $1155(63 \cdot 1)$ & $675(64 \cdot 4)$ & $480(61 \cdot 3)$ \\
\hline $5-18$ years & $278(15 \cdot 2)$ & $169(16 \cdot 1)$ & $109(13 \cdot 9)$ \\
\hline Patients with underlying disease ${ }^{\mathrm{c}}, N(\%)$ & $467(25 \cdot 5)$ & $232(22 \cdot 0)$ & $235(30 \cdot 0)$ \\
\hline Patients with immunosuppressive condition ${ }^{\mathrm{d}}, N(\%)$ & $105(5 \cdot 7)$ & $35(3 \cdot 3)$ & $70(8 \cdot 9)$ \\
\hline Patients with complications ${ }^{\mathrm{e}}, N(\%)$ & $851(46 \cdot 5)$ & $326(31 \cdot 1)$ & $525(67 \cdot 1)$ \\
\hline Length of admission (median (IQR) max) & _- & _ & $2(1,4) 74$ \\
\hline
\end{tabular}

${ }^{a}$ Defined as patients registered as outpatients or inpatients for $<1$ day.

${ }^{\mathrm{b}}$ Defined as patients registered as inpatients for $\geqslant 1$ day.

${ }^{\mathrm{c}}$ Defined as being registered with an ICD10 diagnosis compatible with underlying medical condition in the Danish National Patient Register up to 5 years before and 3 weeks after the varicella diagnosis.

${ }^{\mathrm{d}}$ Defined as being registered with cancer disease, auto immune disease or other immunosuppressive conditions in the Danish National Patient Register up to 5 years before and 3 weeks after the varicella diagnosis.

${ }^{\mathrm{e}}$ Defined as being registered with an ICD10 diagnosis compatible with complications of varicella in the Danish National Patient Register at time of hospitalization for varicella.

years, IQR (2-6)) than patients with a western region (Denmark and Europe) of birth (median age 2 years, IQR (1-3)).

The overall incidence of hospitalization with varicella was $26 / 100000$ children $0-18$ years of age/year. The incidence of children with outpatient contacts was $15 / 100000$ children $0-18$ years of age/year and the incidence of admissions lasting $\geqslant 1$ day was $11 /$ 100000 children $0-18$ years of age/year (Table 3). The highest incidence of hospitalization was in the Capital Region of Denmark. The highest age-specific incidence was in children $<2$ years of age (Fig. 3).

We identified one death; a 7-year-old boy born in Asia and previously registered in DNPR with iridocyclitis on numerous occasions indicating autoimmune disease. He was registered as hospitalized with encephalitis and pneumonia due to varicella as well as endocarditis. He died after 14 days of admission. The mortality rate was $0 \cdot 014 / 100000$ children $0-18$ years of age/year.

\section{Logistic regression analysis}

After excluding 1138 children randomly selected as referents from CRS, the total number of referents used for analysis was 17182 children including 35 cases $(0 \cdot 2 \%)$. A total of $1731(10 \cdot 1 \%)$ referents were registered with underlying disease using the same criteria as for cases.
Table 4 presents results of uni- and multivariable analysis of determinants for any kind of hospital contact with varicella. All categories of underlying medical conditions increased the odds of hospitalization, but the greatest odds were found in patients with cancer and autoimmune disease with odds ratios of $17 \cdot 0(95 \%$ CI $8 \cdot 6-33 \cdot 3)$ and $12 \cdot 0$ (95\% CI 7.5-19.3), respectively. Furthermore, not being born in Denmark and male sex raised the odds of hospitalization.

Table 5 presents results of uni- and multivariable analysis with admission $\geqslant 1$ day as the outcome among the 1832 patients hospitalized with varicella. Cancer disease, autoimmune disease, age $<1$ year and complications to varicella raised the odds of being admitted $\geqslant 1$ day.

\section{DISCUSSION}

The incidence of paediatric varicella admissions $\geqslant 1$ day was $11 / 100000$ children $0-18$ years of age. This is lower than reported from other European countries including France, Belgium and Spain with incidences of admissions of 28-30/100 000 children 0-16 years of age and 23/100 000 children $0-14$ years of age, respectively [12, 21, 22], but in line with estimates from Germany, Italy and Sweden [13, 23, 24]. Due to vast differences in study design and healthcare systems, it is difficult to compare incidences and the epidemiology of varicella across European countries. 
Table 2. Complications ${ }^{a}$ in paediatric patients admitted with varicella in Denmark 2010-2016

\begin{tabular}{lll}
\hline \hline & All patients $^{\mathrm{b}}$ & Admitted patients \\
$N=1832$, & $N=783$, \\
& $N(\%)$ & $N(\%)$ \\
Organ system & $851(46 \cdot 5)$ & $525(67 \cdot 1)$ \\
\hline Any complication & $111(6 \cdot 1)$ & $63(8 \cdot 0)$ \\
Unspecified & $227(12 \cdot 4)$ & $137(17 \cdot 5)$ \\
Central nervous system & $147(8 \cdot 0)$ & $76(9 \cdot 7)$ \\
Febrile seizure & $53(2 \cdot 9)$ & $43(5 \cdot 5)$ \\
Encephalitis/meningitis/ & & \\
$\quad$ myelitis & $10(0 \cdot 6)$ & $10(1 \cdot 3)$ \\
Ataxia & $3(0 \cdot 2)$ & $2(0 \cdot 3)$ \\
Stroke/cerebral vasculitis & $128(7 \cdot 0)$ & $86(11 \cdot 0)$ \\
Skin & $104(5 \cdot 7)$ & $74(9 \cdot 5)$ \\
Infection of skin and soft & \\
$\quad$ tissue & $120(7 \cdot 0)$ & $85(10 \cdot 9)$ \\
Lower airways & $47(2 \cdot 6)$ & $36(4 \cdot 6)$ \\
Pneumonia & $108(5 \cdot 9)$ & $77(9 \cdot 8)$ \\
Dehydration & $95(5 \cdot 2)$ & $45(5 \cdot 8)$ \\
Upper airways & $49(2 \cdot 7)$ & $30(3 \cdot 8)$ \\
Gastrointestinal & $42(2 \cdot 3)$ & $27(3 \cdot 5)$ \\
Gastroenteritis & $3(0 \cdot 2)$ & $2(0 \cdot 3)$ \\
Appendicitis & $28(1 \cdot 5)$ & $24(3 \cdot 1)$ \\
Heart and circulation & $17(0 \cdot 9)$ & $17(2 \cdot 2)$ \\
Sepsis & $2(0 \cdot 1)$ & $2(0 \cdot 3)$ \\
Myocarditis/endocarditis & $24(1)$ & $15(2)$ \\
Muscular skeletal system & $5(0 \cdot 3)$ & $5(0 \cdot 6)$ \\
Septic arthritis/ & & \\
$\quad$ osteomyelitis & $20(1 \cdot 1)$ & $13(1 \cdot 7)$ \\
Urinary and kidney & $14(0 \cdot 8)$ & $8(1 \cdot 0)$ \\
Urinary tract infection & $6(0 \cdot 3)$ & $5(0 \cdot 6)$ \\
Glomerulonephritis & $17(0 \cdot 9)$ & $10(1 \cdot 3)$ \\
Eyes & & \\
\hline
\end{tabular}

The table display number of children registered with ICD10 codes compatible with complications to varicella distributed on organ systems. Number of children with specific complications within an organ system are shown when found important. Patients can be registered with multiple complications and appear more than once.

${ }^{\text {a }}$ Defined as being registered with an ICD10 diagnosis compatible with complications of varicella in the Danish National Patient Registry at the time of hospitalization for varicella.

${ }^{\mathrm{b}}$ All patients refers to all outpatients and admitted patients collectively.

${ }^{\mathrm{c}}$ Defined as being registered with an ICD10 diagnosis of B019 (varicella with other complication) and no other ICD10 codes compatible with complications in the Danish National Patient Register at the time of hospitalization for varicella.

Although we took advantage of national registries, our study has several limitations, including the retrospective approach and the possible underestimation of the incidence of varicella hospitalizations that can occur because of error in ICD10 coding in clinical practice. The DNPR is generally considered of high quality, but it is possible that not all patients with varicella-related hospitalizations are coded with a varicella code. This could particularly be true when varicella complications are the main reason for hospitalization. In a previous prospective study of varicella hospitalizations in four paediatric departments [25], we found that the sensitivity of DNPR was $74 \%$ and applied, this could mean that the 'true' incidence of varicella admissions in Denmark is $15 / 100000$ children $0-18$ years of age rather than $11 / 100000$. However, including children with temporary CRS number and four residents of Greenland may result in some overestimation. Overestimation is also a possibility if the positive predictive value of a varicella ICD10 code in DNPR is low, but we believe that the characteristic clinical features of varicella will lead to very few patients receiving a varicella discharge code if they are not ill from varicella.

The incidence of varicella in a country like Denmark is assumed to be approximately the size of a birth cohort [13] and applied to Denmark with a birth cohort of $\approx 60000$ children, the incidence of admissions due to varicella is $2 / 1000$ cases of varicella (assuming that all cases happen in children $<18$ years of age). This is also in line with what has been found elsewhere in Europe [13, 24, 26].

A total of $67 \cdot 1 \%$ of children admitted $\geqslant 1$ day with varicella were registered with additional ICD10 codes compatible with complications. Though this number is also subject to possible underestimation, our finding corresponds well with other European countries - reported complication rates in Germany and Belgium are $65-80 \%[12,13]$. The distribution of complications vary across studies with skin complications being the most common complications in some studies and neurological in others [15]. The differences are probably due to study design, definition of complications, ascertainment bias and the organization of healthcare systems. In Denmark, most minor complications to varicella like secondary skin infections will be handled by the family doctor and thus never be registered in DNPR. A limitation of the present study was that $8.0 \%$ of patients were registered with an ICD10 code of B018 for varicella with other complication, making it impossible to classify the complication within a specific organ system. We found skin complications in $11.0 \%$ of admitted children and neurological complications in $17 \cdot 5 \%$, although lower numbers than in other studies, the pattern of complications is similar [15]. Of importance, the frequency of complications was not higher in patients with 
Table 3. Incidence of paediatric varicella hospitalizations ${ }^{a}$ in the five regions of Denmark 2010-2016

\begin{tabular}{lllllll}
\hline \hline & $\begin{array}{l}\text { Capital } \\
\text { Region }\end{array}$ & $\begin{array}{l}\text { Region } \\
\text { Zealand }\end{array}$ & $\begin{array}{l}\text { Region of Southern } \\
\text { Denmark }\end{array}$ & $\begin{array}{l}\text { Central } \\
\text { region }\end{array}$ & $\begin{array}{l}\text { North } \\
\text { region }\end{array}$ & $\begin{array}{l}\text { All } \\
\text { regions }\end{array}$ \\
\hline $\begin{array}{l}\text { All hospital contacts (no. cases/annual } \\
\text { incidence/100 000) }\end{array}$ & $644(30)$ & $296(28)$ & $395(25)$ & $359(21)$ & $138(19)$ & $1832(26)$ \\
$\begin{array}{c}\text { Outpatients (no. cases/annual } \\
\text { incidence/100 000) }\end{array}$ & $426(20)$ & $157(15)$ & $198(13)$ & $205(12)$ & $63(9)$ & $1049(15)$ \\
$\begin{array}{c}\text { Admissions } \geqslant 1 \text { day (no. cases/annual } \\
\text { incidence/100 000) }\end{array}$ & $218(10)$ & $139(13)$ & $197(13)$ & $154(9)$ & $75(10)$ & $783(11)$ \\
\hline
\end{tabular}

${ }^{a}$ Hospitalization defined as all in- and outpatient contacts.

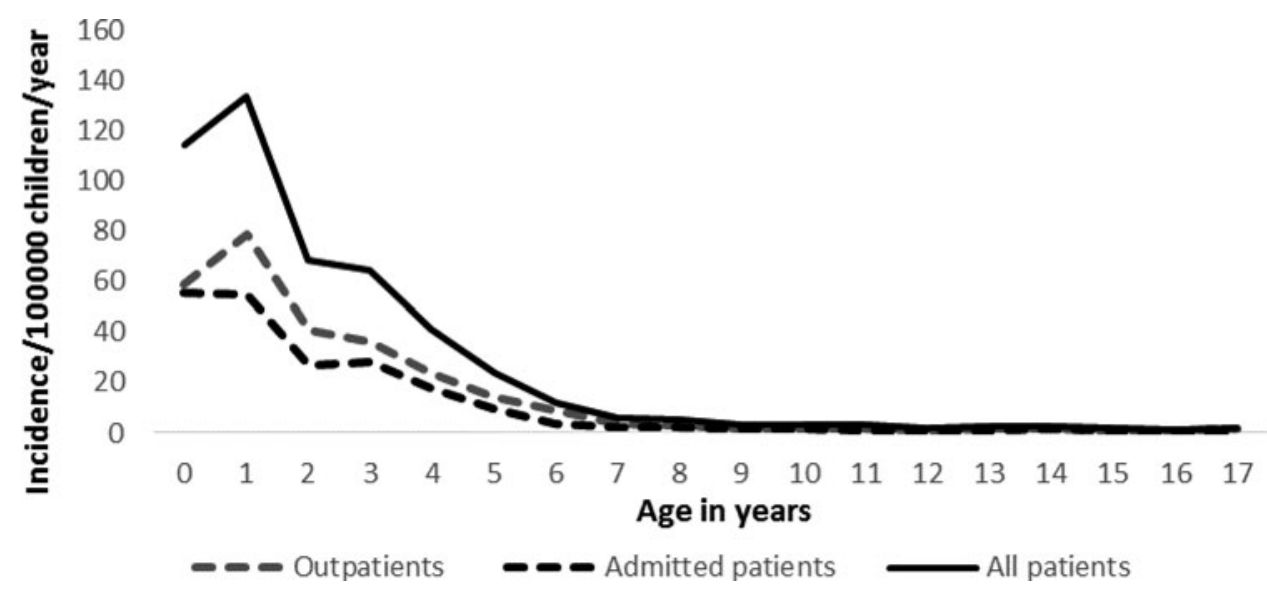

Fig. 3. Age-specific incidence of paediatric varicella hospitalizations in Denmark 2010-2016.

immunosuppression (or overall in children with underlying disease) and could thus be prevented by vaccination. Children with underlying medical conditions comprised $29 \cdot 8 \%$ of admitted children and only $8.9 \%$ were immunosuppressed - well in line with results from other countries when taking varying definitions of underlying conditions in to account [15].

A major strength of our study is the application of a case-cohort design to compare hospitalized children with varicella to a random sample of the source population of all children 0-18 years of age in Denmark. The aim was to assess if children with underlying diseases were more likely to be hospitalized with varicella than the general population. We considered the application of a case-control design, but found that this was a problematic approach since varicella is a very common disease followed by immunity. We did not have information on ongoing or previous nonhospitalized varicella disease in the general population. Hence, we were unable to exclude children with a history of varicella (and therefore no longer at risk of varicella) from a control population. Among others, the case-cohort study differs from a standard case-control study because cases are allowed to be part of the reference group. This makes the casecohort study a good representation of the corresponding cohort study and the estimated odds ratio a valid estimation of the risk ratio [27].

For all categories of underlying medical conditions, the odds for hospitalization with varicella were raised. This is not surprising since these children have closer contact to the secondary healthcare system regardless of varicella disease. The parents are likely to take contact to a hospital rather than a general practitioner or be referred more often. Children with immunosuppressive conditions are in higher risk of a serious course of varicella disease and make hospital contact when exposed to or developing varicella and are treated with acyclovir. We consider this to be the most important reason for the increased odds of being hospitalized for children with underlying disease. That the proportion of children with complications was not higher in children with underlying medical conditions could be an indication of the effectiveness of antiviral 
Table 4. Results of logistic regression analysis of determinants for paediatric varicella hospitalization in Denmark 2010-2016

\begin{tabular}{|c|c|c|c|c|c|c|c|c|}
\hline \multirow[b]{2}{*}{ Variable } & \multirow{2}{*}{$\begin{array}{l}\text { Cases }^{\mathrm{a}} \\
N=1832, N(\%)\end{array}$} & \multirow{2}{*}{$\begin{array}{l}\text { Referents } \\
N=17182, N(\%)\end{array}$} & \multicolumn{3}{|c|}{ Univariable analysis $^{\mathrm{b}}$} & \multicolumn{3}{|c|}{ Multivariable analysis $^{\mathrm{c}}$} \\
\hline & & & OR & $95 \% \mathrm{CI}$ & $P$ value & OR & $95 \% \mathrm{CI}$ & $P$ value \\
\hline Cancer disease & $32(1.75)$ & $14(0 \cdot 1)$ & $22 \cdot 8$ & $12 \cdot 1-43 \cdot 0$ & $<0 \cdot 001$ & $17 \cdot 0$ & $8 \cdot 6-33 \cdot 3$ & $<0 \cdot 001$ \\
\hline Autoimmune disease & $49(2 \cdot 7)$ & $34(0 \cdot 2)$ & $14 \cdot 6$ & $9 \cdot 4-22 \cdot 7$ & $<0 \cdot 001$ & $12 \cdot 0$ & $7 \cdot 5-19 \cdot 3$ & $<0 \cdot 001$ \\
\hline Other immunosuppressive conditions & $36(2 \cdot 0)$ & $23(0 \cdot 1)$ & $15 \cdot 4$ & $9 \cdot 1-26 \cdot 1$ & $<0 \cdot 001$ & $6 \cdot 7$ & $3 \cdot 7-12 \cdot 2$ & $<0 \cdot 001$ \\
\hline Central nervous system and neuromuscular disease & $63(3 \cdot 4)$ & $132(0 \cdot 8)$ & $4 \cdot 7$ & $3 \cdot 4-6 \cdot 3$ & $<0 \cdot 001$ & $3 \cdot 6$ & $2 \cdot 6-5 \cdot 0$ & $<0 \cdot 001$ \\
\hline Heart disease & $89(4 \cdot 9)$ & $232(1 \cdot 4)$ & $3 \cdot 7$ & $2 \cdot 9-4 \cdot 8$ & $<0 \cdot 001$ & $2 \cdot 4$ & $1 \cdot 8-3 \cdot 2$ & $<0 \cdot 001$ \\
\hline Lung disease & $140(7 \cdot 6)$ & $525(3 \cdot 1)$ & $2 \cdot 7$ & $2 \cdot 2-3 \cdot 2$ & $<0 \cdot 001$ & $2 \cdot 1$ & $1 \cdot 7-2 \cdot 6$ & $<0 \cdot 001$ \\
\hline Metabolic diseases & $16(0 \cdot 9)$ & $32(0 \cdot 2)$ & $4 \cdot 7$ & $2 \cdot 6-8 \cdot 6$ & $<0 \cdot 001$ & $2 \cdot 9$ & $1 \cdot 4-5 \cdot 8$ & $0 \cdot 003$ \\
\hline Hereditary diseases of the blood and haemophilia & $9(0 \cdot 5)$ & $13(0 \cdot 1)$ & $6 \cdot 6$ & $2 \cdot 8-15 \cdot 4$ & $<0 \cdot 001$ & $6 \cdot 5$ & $2 \cdot 7-15 \cdot 6$ & $<0.001$ \\
\hline Congenital syndromes & $26(1 \cdot 4)$ & $49(0 \cdot 3)$ & $5 \cdot 0$ & $3 \cdot 1-8 \cdot 1$ & $<0 \cdot 001$ & $2 \cdot 6$ & $1 \cdot 5-4 \cdot 4$ & $<0 \cdot 001$ \\
\hline Atopic skin disease & $39(2 \cdot 1)$ & $113(0 \cdot 7)$ & $3 \cdot 3$ & $2 \cdot 3-4 \cdot 8$ & $<0 \cdot 001$ & $2 \cdot 6$ & $1 \cdot 8-3 \cdot 9$ & $<0 \cdot 001$ \\
\hline History of prematurity & $145(7 \cdot 9)$ & $826(4 \cdot 8)$ & $1 \cdot 7$ & $1 \cdot 4-2 \cdot 0$ & $<0 \cdot 001$ & $1 \cdot 4$ & $1 \cdot 1-1 \cdot 7$ & $0 \cdot 001$ \\
\hline Male gender & $1000(54 \cdot 6)$ & $8745(50 \cdot 9)$ & $1 \cdot 2$ & $1 \cdot 1-1 \cdot 3$ & 0.003 & $1 \cdot 1$ & $1 \cdot 0-1 \cdot 2$ & $0 \cdot 031$ \\
\hline Not born in Denmark & $109(6 \cdot 0)$ & $480(2 \cdot 8)$ & $2 \cdot 2$ & $1 \cdot 8-2 \cdot 8$ & $<0 \cdot 001$ & $2 \cdot 4$ & $2 \cdot 0-3 \cdot 0$ & $0 \cdot 010$ \\
\hline
\end{tabular}

${ }^{\mathrm{a}}$ Cases are outpatients and admitted patients.

${ }^{\mathrm{b}}$ Controlled for matching factors (year of birth and year of hospitalization).

${ }^{\mathrm{c}}$ Controlled for matching factors (year of birth and year of hospitalization) and region of residence.

Table 5 Results of logistic regression analysis of determinants for paediatric varicella hospitalization $\geqslant 1$ day in Denmark $2010-2016$

\begin{tabular}{|c|c|c|c|c|c|c|c|c|}
\hline \multirow[b]{2}{*}{ Variable } & \multirow{2}{*}{$\begin{array}{l}\text { Admitted patients } \\
N=783, N(\%)\end{array}$} & \multirow{2}{*}{$\begin{array}{l}\text { Outpatients } \\
N=1049, N(\%)\end{array}$} & \multicolumn{3}{|c|}{ Univariable analysis } & \multicolumn{3}{|c|}{ Multivariable analysis ${ }^{\mathrm{a}}$} \\
\hline & & & OR & $95 \% \mathrm{CI}$ & $P$ value & OR & $95 \% \mathrm{CI}$ & $P$ value \\
\hline Cancer disease & $26(3 \cdot 3)$ & $6(0 \cdot 6)$ & $6 \cdot 0$ & $2 \cdot 44 \cdot 7$ & $<0.001$ & $10 \cdot 0$ & $3 \cdot 9-25 \cdot 6$ & $<0 \cdot 001$ \\
\hline Autoimmune disease & $31(4 \cdot 0)$ & $18(1 \cdot 7)$ & $2 \cdot 4$ & $1 \cdot 3-4 \cdot 3$ & 0.003 & $3 \cdot 8$ & $2 \cdot 0-7 \cdot 2$ & $<0 \cdot 001$ \\
\hline Other immunosuppressive conditions & $21(2 \cdot 7)$ & $15(1 \cdot 4)$ & 1.9 & $1 \cdot 0-3 \cdot 7$ & 0.056 & - & - & - \\
\hline Central nervous system and neuromuscular disease & $36(4 \cdot 6)$ & $27(2 \cdot 6)$ & $1 \cdot 8$ & $1 \cdot 1-3 \cdot 0$ & 0.019 & - & - & - \\
\hline Heart disease & $43(5 \cdot 5)$ & $46(4 \cdot 4)$ & $1 \cdot 3$ & $0 \cdot 8-1 \cdot 9$ & $0 \cdot 276$ & - & - & - \\
\hline Lung disease & $61(7 \cdot 8)$ & $79(7.5)$ & $1 \cdot 0$ & $0 \cdot 7-1 \cdot 5$ & 0.836 & - & _- & - \\
\hline Metabolic diseases & $8(1 \cdot 0)$ & $8(0 \cdot 8)$ & $1 \cdot 3$ & $0 \cdot 5-3 \cdot 6$ & 0.556 & - & - & - \\
\hline Hereditary diseases of the blood and haemophilia & $4(0 \cdot 5)$ & $5(0 \cdot 5)$ & $1 \cdot 1$ & $0 \cdot 3-4 \cdot 0$ & $0 \cdot 918$ & - & - & - \\
\hline Congenital syndromes & $11(1 \cdot 4)$ & $15(1 \cdot 4)$ & $1 \cdot 0$ & $0 \cdot 4-2 \cdot 2$ & 0.964 & - & _- & - \\
\hline Atopic skin disease & $21(2 \cdot 7)$ & $18(1 \cdot 7)$ & $1 \cdot 6$ & $0 \cdot 8-3 \cdot 0$ & $0 \cdot 157$ & - & - & - \\
\hline History of prematurity & $64(8 \cdot 2)$ & $81(7 \cdot 7)$ & $1 \cdot 1$ & $0 \cdot 8-1 \cdot 5$ & $0 \cdot 723$ & - & - & - \\
\hline Age $<1$ year & $194(24 \cdot 8)$ & $205(19 \cdot 5)$ & $1 \cdot 4$ & $1 \cdot 1-1 \cdot 7$ & 0.007 & 1.9 & $1 \cdot 5-2 \cdot 4$ & $<0 \cdot 001$ \\
\hline Male gender & $434(55 \cdot 4)$ & $566(54 \cdot 0)$ & $1 \cdot 1$ & $0 \cdot 9-1 \cdot 3$ & $0 \cdot 531$ & - & - & - \\
\hline Complications to varicella & $525(67 \cdot 1)$ & $326(31 \cdot 1)$ & $4 \cdot 5$ & $3 \cdot 7-5 \cdot 6$ & $<0 \cdot 001$ & $4 \cdot 9$ & $4 \cdot 0-6 \cdot 1$ & $<0 \cdot 001$ \\
\hline Not born in Denmark & $31(4 \cdot 0)$ & $78(7 \cdot 4)$ & 0.5 & $0 \cdot 3-0 \cdot 8$ & 0.002 & - & - & - \\
\hline
\end{tabular}

${ }^{\mathrm{a}}$ Controlled for year and region of hospitalization. 
medication against VZV. Male sex also increased the odds of a hospital contact; the reason for this overweight of males is not clear but has also been observed in other studies [13, 14].

With this study, we have provided baseline data on the epidemiology of hospitalized children with varicella in Denmark. Varicella vaccination has shown to be very effective against severe disease and the majority of the admissions described in this study could potentially be averted [4]. However, there are other important factors to be considered when discussing implementation of mass varicella vaccination. Varicella is most often a mild disease that most children will recover from without sequelae and it is followed by lifelong immunity. If vaccination coverage is not high enough, a rise in morbidity and mortality is a risk due to a shift in age of primary infection. Furthermore, the duration of immunity to varicella after vaccination is still not established and waning of immunity could also lead to a shift of varicella to the adult population. Studies from the USA and Germany does not indicate that a shift in age of primary infection has taken place so far [6, 9], but sufficient time since introduction of varicella vaccination may not have passed for this effect to be visible yet. A recent study of VZV seropositivity in $>10000$ US air force recruits found that varicella vaccinated individuals were $24 \%$ less likely to be seropositive to VZV than those who experienced natural varicella infection. The odds of vaccinated individuals being seropositive decreased by $8 \%$ with each year since vaccination [28]. Furthermore, less circulation of wild varicella virus might lead to an increase in herpes zoster in adults according to the exogenous boosting theory proposed by Hope-Simpson [29]. Mathematical models have shown a potential rise in adult herpes zoster after childhood varicella vaccination [30]. The impact of mass varicella vaccination on the incidence of herpes zoster has been debated since the introduction of varicella vaccination in the childhood vaccination programme in the USA in 1995. The subject of exogenous boosting remains a concern that needs to be further studied as results of studies examining the effect of mass varicella vaccination on the incidence of herpes zoster in adults are not uniform $[1,31]$. Some studies have shown a rise in herpes zoster incidence and hospitalizations since the introduction of varicella vaccination, while other studies have not demonstrated a rise or argue that the rise in incidence was apparent even before introduction of vaccination $[1,10,11,31-34]$. Even if exogenous boosting does exist, it is still not clear to what extent it influences VZV epidemiology [35].

\section{CONCLUSION}

With this unique and nationwide study, we have provided a baseline from which to begin discussions on possible introduction of varicella vaccination in Denmark. The burden of paediatric varicella disease in Danish hospitals is considerable and by and large of the same magnitude as what has been found in other European countries comparable to Denmark. Some of these countries, like Germany, have chosen to implement universal varicella vaccination. Additional factors have to be taken in to account when considering implementation, but epidemiological data on the paediatric population, who bear the greatest burden, are the first important step in gathering evidence for a decision process.

\section{SUPPLEMENTARY MATERIAL}

The supplementary material for this article can be found at https://doi.org/10.1017/S0950268817001777.

\section{ACKNOWLEDGEMENTS}

The authors would like to thank Michael Galle and Jens Nielsen, Statens Serum Institute, for assistance.

This work was supported by an unrestricted grant from GlaxoSmithKline to the Department of Paediatrics and Adolescent Medicine, Rigshospitalet, Copenhagen, Denmark

\section{DECLARATION OF INTEREST}

I. G. Helmuth has received research funding for her Ph.D. study on varicella epidemiology through an unrestricted grant from GlaxoSmithKline to the Department of Paediatrics and Adolescent Medicine, Rigshospitalet, Copenhagen, Denmark. All other authors have no conflicts of interest to declare

\section{REFERENCES}

1. Gershon AA, Gershon MD. Pathogenesis and current approaches to control of varicella-zoster virus infections. Clinical Microbiology Reviews 2013; 26(4): 728 743. doi: 10.1128/CMR.00052-13.

2. Heininger U, Seward JF. Varicella. Lancet 2006; 368 (9544): 1365-1376. doi: 10.1016/S0140-6736(06)69561-5.

3. Nardone A, et al. The comparative sero-epidemiology of varicella zoster virus in 11 countries in the European 
region. Vaccine 2007; 25(45): 7866-7872. doi: 10.1016/j. vaccine.2007.07.036.

4. Marin M, et al. Global varicella vaccine effectiveness: a meta-analysis. Pediatrics 2016; 137(3): e20153741. doi: 10.1542/peds.2015-3741.

5. World Health Organisation. Varicella and herpes zoster: WHO position paper. Weekly Epidemiogical Record 2014; 89(25): 265-287.

6. Baxter R, et al. Impact of vaccination on the epidemiology of varicella: 1995-2009. Pediatrics 2014; 134(1): 24-30. doi: 10.1542/peds.2013-4251.

7. Streng A, Liese JG. Fifteen years of routine childhood varicella vaccination in the United States-strong decrease in the burden of varicella disease and no negative effects on the population level thus far. Translational Pediatrics 2014; 3(4): 268-272. doi: 10.3978/j.issn.2224-4336.2014. 10.02 .

8. Siedler A, Dettmann M. Hospitalization with varicella and shingles before and after introduction of childhood varicella vaccination in Germany. Human Vaccines \& Immunotherapeutics 2014; 10(12): 3594-3600. doi: 10.4161/hv.34426.

9. Siedler A, Arndt U. Impact of the routine varicella vaccination programme on varicella epidemiology in Germany. Euro Surveillance: Bulletin European Sur Les Maladies Transmissibles $=$ European Communicable Disease Bulletin 2010; 15(13): pii=19530.

10. Heywood AE, et al. Varicella and herpes zoster hospitalizations before and after implementation of one-dose varicella vaccination in Australia: an ecological study. Bulletin of the World Health Organization 2014; 92(8): 593-604. doi: 10.2471/BLT.13.132142.

11. Marin M, Meissner HC, Seward JF. Varicella prevention in the United States: a review of successes and challenges. Pediatrics 2008; 122(3): e744-e751. doi: 10.1542/ peds.2008-0567.

12. Blumental S, et al. Varicella paediatric hospitalisations in Belgium: a 1-year national survey. Archives of Disease in Childhood 2016; 101(1): 16-22. doi: 10.1136/archdischild-2015-308283.

13. Liese JG, et al. The burden of varicella complications before the introduction of routine varicella vaccination in Germany. The Pediatric Infectious Disease Journal 2008; 27(2): 119-124. doi: 10.1097/INF.0b013e3181586665.

14. Hobbelen PHF, et al. The burden of hospitalisation for varicella and herpes zoster in England from 2004 to 2013. The Journal of Infection 2016; 73(3): 241-253. doi: 10.1016/j.jinf.2016.05.008.

15. Helmuth IG, et al. Varicella in Europe-A review of the epidemiology and experience with vaccination. Vaccine 2015; 33(21): 2406-2413. doi: 10.1016/j.vaccine. 2015. 03.055 .

16. European Centre for Disease Prevention and Control. Varicella-Guidance-2015.pdf. http://ecdc.europa.eu/en/ publications/Publications/Varicella-Guidance-2015.pdf [accessed November 22, 2016].

17. Schmidt M, Pedersen L, Sørensen HT. The Danish Civil Registration System as a tool in epidemiology. European Journal of Epidemiology 2014; 29(8): 541-549. doi: 10.1007/s10654-014-9930-3.
18. Schmidt M, et al. The Danish National Patient Registry: a review of content, data quality, and research potential. Clinical Epidemiology 2015; 7: 449-490. doi: 10.2147/ CLEP.S91125.

19. Lynge E, Sandegaard JL, Rebolj M. The Danish National Patient Register. Scandinavian Journal of Public Health 2011; 39(7 Suppl.): 30-33. doi: 10.1177/ 1403494811401482.

20. Den nationale videnskabsetiske komité. dnvk.dk (http:// www.dnvk.dk/CVK/Home/English.aspx). Accessed 7 November 2016.

21. Guillén JM, et al. Varicella paediatric hospitalizations in Spain. Epidemiology and Infection 2009; 137(4): 519-525. doi: 10.1017/S0950268808001131.

22. Dubos F, et al. Epidemiology of hospital admissions for paediatric varicella infections: a one-year prospective survey in the pre-vaccine era. Epidemiology and Infection 2007; 135(1): 131-138. doi: 10.1017/S0950268806006467.

23. Pozza F, et al. Impact of universal vaccination on the epidemiology of varicella in Veneto, Italy. Vaccine 2011; 29 (51): 9480-9487. doi: 10.1016/j.vaccine.2011.10.022.

24. Widgren $\mathbf{K}$, et al. The burden of chickenpox disease in Sweden. BMC Infectious Diseases 2016; 16(1): 666. doi: 10.1186/s12879-016-1957-5.

25. Helmuth IG, et al. Children hospitalized with varicella in Denmark: sensitivity of the National Patient Register. The Pediatric Infectious Disease Journal 2017; 36(1): 31-35.

26. Bonhoeffer $\mathbf{J}$, et al. Prospective surveillance of hospitalisations associated with varicella-zoster virus infections in children and adolescents. European Journal of Pediatrics 2005; 164(6): 366-370. doi: 10.1007/ s00431-005-1637-8.

27. Rothman KJ, Greenland S, Lash TL. Modern Epidemiology. Lippincott: Williams \& Wilkins; 2008.

28. Duncan JR, et al. Varicella seroepidemiology in United States air force recruits: a retrospective cohort study comparing immunogenicity of varicella vaccination and natural infection. Vaccine 2017; 35(18): 2351-2357. doi: 10.1016/j.vaccine.2017.03.054.

29. Hope-Simpson RE. The nature of herpes zoster: a longterm study and a new hypothesis. Proceedings of the Royal Society of Medicine 1965; 58: 9-20.

30. Brisson M, et al. Exposure to varicella boosts immunity to herpes-zoster: implications for mass vaccination against chickenpox. Vaccine 2002; 20(19-20): 2500-2507.

31. Goldman GS, King PG. Review of the United States universal varicella vaccination program: herpes zoster incidence rates, cost-effectiveness, and vaccine efficacy based primarily on the Antelope Valley Varicella Active Surveillance Project data. Vaccine 2013; 31(13): 1680-1694. doi: 10.1016/j.vaccine.2012.05.050.

32. Gil-Prieto R, et al. Different vaccination strategies in Spain and its impact on severe varicella and zoster. Vaccine 2014; 32(2): 277-283. doi: 10.1016/j. vaccine.2013.11.008.

33. Hales CM, et al. Examination of links between herpes zoster incidence and childhood varicella vaccination. Annals of Internal Medicine 2013; 159(11): 739-745. doi: 10.7326/0003-4819-159-11-201312030-00006. 
34. Patel MS, Gebremariam A, Davis MM. Herpes zosterrelated hospitalizations and expenditures before and after introduction of the varicella vaccine in the United States. Infection Control and Hospital Epidemiology 2008; 29(12): 1157-1163. doi: 10.1086/591975.
35. Ogunjimi B, Van Damme P, Beutels P. Herpes zoster risk reduction through exposure to chickenpox patients: a systematic multidisciplinary review. PLoS ONE 2013; 8(6): e66485. doi: 10.1371/journal. pone. 0066485 . 